\title{
Chemical Safety in Academic Laboratories: An Exploratory Factor Analysis of Safe Work Practices \& Facilities in a University
}

\author{
Mohsin Abbas (Corresponding author) \\ Department of Environmental Sciences, \\ Faculty of Meteorology Environment Arid Land Agriculture, \\ King Abdul-Aziz University, Jeddah, Saudi Arabia. \\ Tel: 96-656-091-9478 \\ E-mail: mohsinabbas34@yahoo.com; myousaf@stu.kau.edu.sa. \\ Adel M. Zakaria \\ Department of Environmental Sciences, \\ Faculty of Meteorology, Environment and Arid Land Agriculture, \\ King Abdul-Aziz University, Jeddah, Kingdom Saudi Arabia
}

\author{
Mansour A. Balkhyour \\ Department of Environmental Sciences
}

Faculty of Meteorology Environment Arid Land Agriculture,

King Abdul-Aziz University, Jeddah, Saudi Arabia

\footnotetext{
Muhammad Kashif

${ }^{1}$ Department of Statistic, Faculty of Science, King Abdul-Aziz University, Jeddah, Saudi Arabia

${ }^{2}$ Department of Mathematics and Statistics, University of Agriculture Faisalabad, Faisalabad, Pakistan
}

Received: February 1, 2016 Accepted: March 14, 2016 Published: May 11, 2016

doi:10.5296/jss.v2i1.8962 URL: http://dx.doi.org/10.5296/jss.v2i1.8962 


\begin{abstract}
Academic laboratories considered as more hazardous than industry due to relaxed approach of academic management for chemical safety. This study designed to analyze the safe work practices and facilities by Exploratory Factor Analysis (EFA) using Varimax rotation. A designed checklist of 26 safety items administered personally in 68 academic laboratories in a Saudi university. From EFA, five factors were extracted: "Availability of laboratory safety documents (5 items, $\alpha=0.92$ )", "Maintenance of fume hood (2 items, $\alpha=0.75$ )", "Proper chemical storage (3 items, $\alpha=0.64$ )", "Proper use of fume hood for chemical handling (4 items, $\alpha=0.62$ )" and "Laboratory safety labelling ( 2 items, $\alpha=0.73$ )". The results revealed the 5 factors model that grouped 16 safety items that may be crucial for chemical storage, fume hood, laboratory safety plans and labels in the academic laboratories. The extracted factors derived from EFA are expected to help in the development of chemical safety management in the academic laboratories.
\end{abstract}

Keywords: Factor analysis; Chemical laboratory safety; Kingdom of Saudi Arabia; Checklist

\title{
1. Introduction
}

Surprisingly academic labs were reported more dangerous than industrial one due to the relaxed approach of educational organizations for safety (Peplow \& Marris, 2006; Langerman, 2009). This relaxed attitude for safety in the academia may undermine the institutional goals of education excellence, so to ensure health and safety of laboratory staff is the primary responsibility of academic management (Wu et al., 2007). Laboratory safety must be at top priorities (Hill, 2007), especially in chemical laboratories that involve handling of chemicals. Academic laboratories are rarely inspected due to limited resources such as; professional staff $\&$ underestimation of laboratory safety (Marendaz et al., 2013).

Meyer (2015) discussed the implementation of safety education strategies to improve the safety level in a research and teaching institution, and safety level can be improve through the involvement of all laboratory staff member. Lestari et al. (2015) administrated a checklist survey on the implementation of chemical safety in the laboratories of health faculties. They found a limited number of laboratories equipped with emergency spill kits and lack of an emergency team that express a lack of resources and inadequate safety facilities. They concluded that $63 \%$ of the surveyed laboratories have Laboratory chemical safety, health \& security compliance below 50\%, and they also suggested regular inspections to improve it. Mogopodi et al. (2015) did an assessment study about chemical management and safety practices in junior secondary school laboratories. They found the lack of safety knowledge \& awareness, poor record keeping, improper chemical inventory management and lack of measures for out-of-date chemical stock or expired chemicals. Deficiencies regarding improper chemical containers labelling, incompatible chemical storage. It was suggested to include chemical safety education in study curriculum for laboratory safety improvement. Kristopher et al. (2013) made a questionnaire study about the preliminary evaluation of safe work practices of laboratory technicians in a university and found deficiencies regarding 
proper use of PPE, labelling \& posting. Karapantsios et al. (2008) \& Artdej (2012) used an anonymous questionnaire to assess students' scientific knowledge of laboratory chemicals labelling. Poor performance regarding chemical labelling according to their safety sign has been evaluated. Richards-Babb et al. (2010) administrated a Likert scale survey and found that chemical laboratories are inadequate for projected students enrollment needs, lack of inspection of safety equipment, formalized safety training, sufficient laboratory facilities and pre-service. It found a lack of laboratory safety training and that chemical management was not teach to the chemistry teachers during their study period, so they emphasize on it. As in a recent study, it was investigated that $61 \%$ of laboratory staff who were at risk of chemical exposure had never received any chemical safety training (Mogopodi et al., 2015).

As this study conducted in a Saudi university and there are limited studies about the laboratory safety in the KSA such as; Balkhiour, (2011) and Abbas et al.2015 designed assessment studies about laboratory safety in Saudi universities and average results attained in terms of safety facilities and safe work practices.

In the present study, Exploratory Factor Analysis (EFA) that used broadly for statistical analysis was applied to chemical research \& teaching laboratories at a Saudi university. EFA is one of the multivariate data analyses, utilized to discover the latent variables that underlie any scale. Previously Factor analysis used to determine the latent variables of safety awareness among laboratory research staff in Japan (Shuhara et al., 2011). By applying EFA method to questionnaire results, the goals of this study are to investigate factors that compose of chemical storage, fume hood, laboratory safety plans and labels which are crucial for chemical safety in research \& teaching laboratories.

\section{Materials and Methods}

\subsection{Instruments}

For this study the survey inspection checklist tailored to the "Prudent Practices in the Laboratory: Handling and Management of Chemical Hazards" developed by National Research Council (NRC, 2011). This laboratory safety checklist composed of 26 items (18+ 8) about chemical storage, fume hood, laboratory safety plans and labels. Total eighteen laboratory safety items directly taken from the developed checklist and eight laboratory safety items included according to the selected on of Saudi University appropriateness for the chemical storage, fume hood, laboratory safety plans and labels. The survey checklist also discussed with an expert and chemical laboratory staff to check the suitability of the safety items. Three types of questions asked during the investigation such as "Yes", "No" or not applicable if the safety item does not apply. The laboratory survey checklist comprised of 26 safety items (including eight items of chemical storage, a chemical hood, laboratory safety plans and labels) in the fifteen chemistry department laboratories of the selected university. Before this survey, we took approval from the university's higher administrations. Cronbach's $\alpha$ coefficient was calculated for designed 26 safety items checklist to check the internal consistency and found 0.78 which was an acceptable range. SPSS version 15.0 was used for EFA and the Principal Component Analysis (PCA) with Varimax rotation applied to this study. 


\subsection{Sampling and Data Collection}

The designed checklist filled personally by one of the authors in each chemical laboratory, in contrast, to distribute to the laboratory staff. All those laboratories that use chemicals considered as chemical laboratories or chemistry laboratories. The selected Saudi University's academic departments and research Excellency centers selected for lab safety inspection and the survey carried from November 2014 to April 2015. Table 1 summarized the laboratory safety sample feature. Descriptive data of chemical laboratories acquired through designed checklist provided in Table 2.

Table 1. Laboratories sample features

\begin{tabular}{llc} 
Variables & $\mathrm{N}$ & $\%$ \\
\hline Gender & & \\
Male & 68 & 100.0 \\
Female & 0 & 0.0 \\
\hline
\end{tabular}

\section{Occupational group}

Staff/Technicians

Students

$14 \quad 20.6$

\section{Types of laboratories}

Research

$40 \quad 58.8$

Teaching

$28 \quad 41.2$

\section{Laboratories academic Field}

Chemistry

Biological Sciences

$10 \quad 14.7$

Biochemistry

$6 \quad 8.8$

Medicine

$3 \quad 4.4$

Earth Sciences

2

2.9

Environmental Sciences

$\begin{array}{ll}6 & 8.8\end{array}$

Chemical and Materials Engineering

$\begin{array}{ll}7 & 10.3\end{array}$

Pharmacy

$11 \quad 16.2$

Research Excellence centers Labs

8

11.8


Table 2. Descriptive data for Laboratory Safety Items

Laboratory Safety Items (26 items) Mean S.D.

Laboratory Safety Documents (LSD- 6 items)

LSD01: Updated Lab safety Manual is available

$1.10 \quad 0.31$

LSD02: Updated Chemical hygiene plan is available

$1.10 \quad 0.31$

LSD03: Updated Emergency action plan is available

1.120 .32

LSD04: Updated Spill response guide is available

$1.10 \quad 0.31$

LSD05: Safety data Sheets are available (MSDS)

$1.26 \quad 0.44$

LSD06: Updated Lab chemicals inventory are available

$1.56 \quad 0.50$

Chemical Storage \& Labelling (CS- 11 items)

CSL01: Shelving adequate for chemicals loads imposed

$0.31 \quad 0.50$

CSL02: Chemical containers clearly labeled with contents

$1.24 \quad 0.43$

CSL03: Chemicals are segregated by hazards class such as flammable, $\begin{array}{lll}1.65 & 0.48\end{array}$ corrosive and oxidizers etc.

CSL04: Refrigeration units label with "No Food" tag

CSL05: Chemical storage cabinets are labelled properly

CSL06: Corrosive chemical stored below eye level

CSL07: Volatile chemicals are stored in unventilated locations labs.

$1.04 \quad 0.40$

CSL08: Glass chemicals are not stored on the floor

$1.41 \quad 0.50$

CSL09: Expired or chemicals not used are disposed of as hazardous waste

CSL10: Large/heavy chemical containers stored on lower shelves

CSL11: Flammable storage cabinets used for flammables storage.

Fume hood \& $\mathrm{CH}$ (FH-9)

FHCH01: Fume hood is functional

FHCH02: Fume hood is not used as permanent storage for chemicals

FHCH03: Chemical fume hood has been tested within last year

FHCH04: Fume hood vents (baffles) unobstructed

$1.60 \quad 0.49$ 
FHCH06: Sash is closed when not in active use

$1.12 \quad 0.32$

FHCH07: Chemical containers kept closed after chemical transfer

$1.87 \quad 0.34$

FHCH08: Chemicals and equipment are at least 6 inches from the sash

$1.13 \quad 0.42$

FHCH09: Secondary containment used near sinks and drains

$1.75 \quad 0.44$

\section{Results and Discussion}

EFA used in this study to extract chemical safety factors that are crucial to laboratory safety in a university. EFA performed on the model composed of 5 latent variables, 17 observed variables and 17 latent variables structure of the extracted factors shown in Fig. 1.

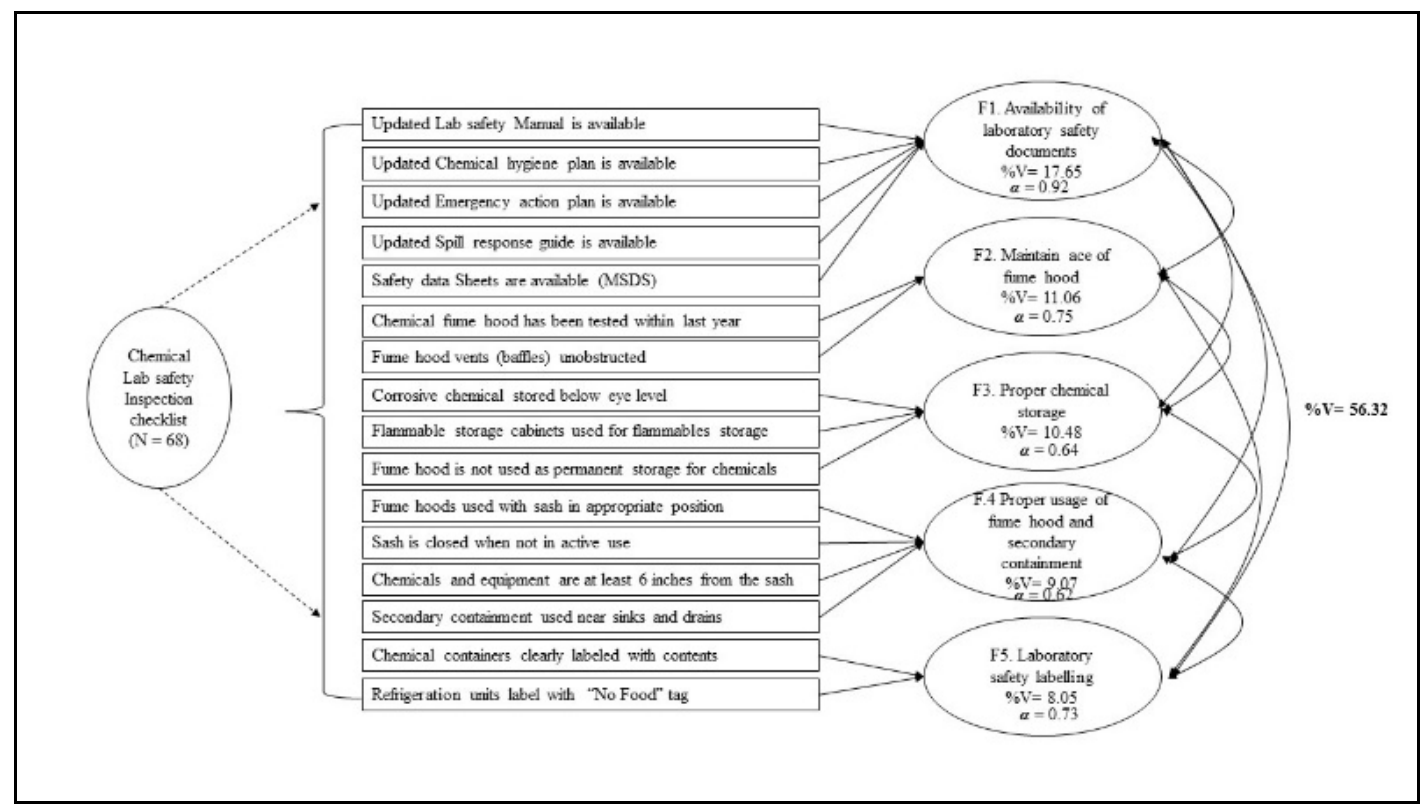

Figure 1. Five factor model solution on chemical safety in university research and teaching laboratories

The latent variable is a factor derived from EFA. The observed variable is a response to the safety item grouped into a factor showing high factor loading in EFA. The error variable is a factor other than those analyzed in EFA.

The results of exploratory factor analysis (EFA) displays the relationship between the factors and the items directly asking about the chemical storage, chemical handling, fume hood, laboratory safety documents were examined. PCA extracted five factors with eigenvalues exceeding 1. There was a clear break after the third factor so, a five-factor solution adopted which represented $56 \%$ of the total variance. Table 3 shows the factor loadings, Percentage of factor variance, Percentage of cumulative variance, Eigenvalues and Cronbach $\alpha$ for the EFA. 


\section{Macrothink

The results of EFA produced five factors solution and their logical groupings of variables explain $56.31 \%$ of the total variance. The reliability analysis of 5-factor model in Table 3 verifies the reliability of the scales (Nunnally, 1987).

Table 3. Factor Analysis (Principal Component Analysis with Varimax rotation of Laboratory Safety items

Laboratory Safety items

\begin{tabular}{lllll} 
Factor & & & \\
\hline 1 & 2 & 3 & 4 & 5
\end{tabular}

Factor 1. Avilability of laboratory safety documents

LSD03: Updated Emergency action plan is available

0.955

LSD04: Updated Spill response guide is available

0.944

LSD01: Updated Lab safety Manual is available

LSD02: Updated Chemical hygiene plan is available

LSD05: Safety data Sheets are available (MSDS)

Factor 2. Maintenance of fume hood

FHCH03: Chemical fume hood has been tested within last year

0.813

0.757

FHCH04: Fume hood vents (baffles) unobstructed

Factor 3. Proper chemical storage

CSL06: Corrosive chemical stored below eye level

CSL11: Flammable storage cabinets used for flammables storage

FHCH02: Fume hood is not used as permanent storage for chemicals

Factor 4. Proper use of fume hood for chemical handling

FHCH06: Sash is closed when not in active use

FHCH05: Fume hoods used with sash in appropriate position

FHCH08: Chemicals and equipment are at least 6 inches from the sash

FHCH09: Secondary containment used near sinks and drains

\section{Factor 5. Laboratory safety labelling}

CSL04: Refrigeration units label with "No Food" tag

CSL02: Chemical containers clearly labeled with contents

Percentage of factor variance

$\begin{array}{lllll}17.65 & 11.06 & 10.48 & 9.07 & 8.05\end{array}$

Percentage of cumulative variance

$\begin{array}{lllll}17.65 & 28.71 & 39.19 & 48.27 & 56.32\end{array}$

Eigenvalues

5.02

2.98

2.83

2.22

1.61

Cronbach $\alpha$

0.92

0.75

0.64

0.62

0.73 
A Varimax rotation performed to enrich factor interpretability. All five factors were studied to investigate the number of items that loaded on each extracted factor. For practical significance, factor loadings were restricted to 0.5 and above. There was a total of 12 items on the scale. Eight safety items had a factor loading less than 0.5 (recommended level).

The following items removed: LSD06: Updated Lab chemicals inventory are available; CSL01: Shelving adequate for chemicals loads imposed; CSL03: Chemicals segregated by hazards class such as flammable, corrosive and oxidizers, etc.; CSL05: Chemical storage cabinets are labelled properly; CSL07: Volatile chemicals are stored in unventilated locations labs; CSL08: Glass chemicals are not stored on the floor; CSL09: Expired or chemicals not used are disposed of as hazardous waste (e.g. Peroxide forming chemicals); CSL10: Large/heavy chemical containers stored on lower shelves; FHCH01: Fume hood is functional and FHCH07: Chemical containers kept closed after chemical transfer. All five factors were labelled subjectively according to their basic set of individual items. The ordering of all safety Items organized into their descending order by their volume of variance explained to determine essential features of the factor. The Varimax-rotated factor pattern implied and following five factors labeled logically such as;

Factor 1.Avilability of laboratory safety documents ( 5 items, $\alpha=0.92$ )

Factor 2. Maintenance of fume hood (2 items, $\alpha=0.75$ )

Factor 3. Proper chemical storage (3 items, $\alpha=0.64$ )

Factor 4. Proper use of chemical handling accessories (4 items, $\alpha=0.62$ )

Factor 5. Laboratory safety labelling (2 items, $\alpha=0.73$ )

\subsection{Factor 1. Avilability of Laboratory Safety Documents}

The first factor, Availability of laboratory documents comprise of five safety items and accounts for $17.65 \%$ of the total variance. All essential safety items in the first factor indicate that the availability of laboratory safety documents is vital to ensure the safety in chemical laboratories. The development of laboratory safety documents is necessary to put a sound framework for laboratory staff. The emergency action plan must include procedures for fires, chemical spills, evacuation, ventilation failure, medical emergencies, and incident reporting. (Foster, 2004).

The development of Chemical Hygiene Plan (CHP) also showed high factor loading. As it mentioned in the OSHA Laboratory Standard 29 CFR 1910.1450 that employers shall have developed and implemented a written CHP, its recommendations should be followed in academic teaching laboratories as well as by full-time laboratory workers (OSHA Laboratory Standard 29 CFR 1910.1450). The development of departmental CHP is necessary to protect laboratory staff from chemical exposure. Details can be adopted such as emergency reporting flow, evacuation routes, assigned assembly for workers and accountability procedures from emergency action plan that is useful to cope with the emergency situations. Material Safety Data Sheets (MSDS) can be helpful to take valuable information about chemical handling and associated risk and safety measures, as it is a requirement of OSHA 29 CFR, Part 


\section{Macrothink}

1910.1200.3. MSDS file must keep on the premises of laboratory (Foster, 2004). There should be access to the laboratory staff for MSDS, departmental \& institutional emergency action plan and CHP (Foster, 2004). Overall Items of the first factor expressed high loading unlikely to the rest of the factors. The limited response regarding laboratory safety documents such as safety manual (safety policies) found in a study (Richards-Babb et al., 2010).

\subsection{Factor 2. Maintenance of Fume Hood}

The second factor, maintenance of fume hood contains two items and account for $11.06 \%$ of the total variance. This factor deals with the importance of university's inspection of fume hoods to ensure the safety in chemical laboratories. The blockage of exhaust slots by containers and equipment can affect the airflow as figure 2 shows a severely managed fume hood by laboratory staff which displays a lack of inspection at any level. Maintenance of fume hood in the chemical laboratories can be ensured through the implementation of university inspection plan at the departmental level. The slots and baffles at the back of the hood should be unobstructed as standard practices.

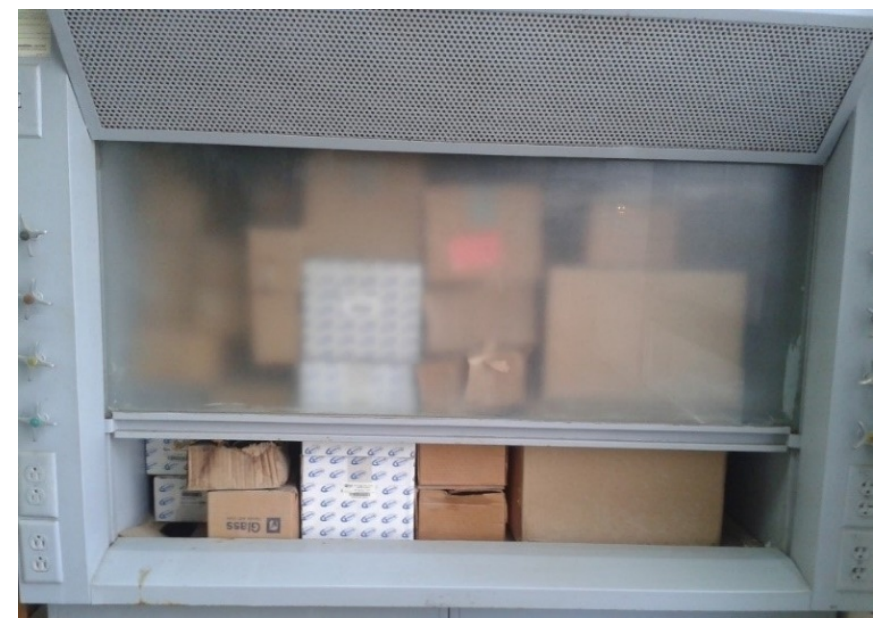

Figure 2. Severely managed Fume hood with extensive storage

Fume hood is an integral part of any chemical lab as the first line of safety measure, which can prevent laboratory workers from harmful exposure to hazardous fumes and vapors by continuous drawing filtered and conditioned air out of the laboratory. Previously Richards-Babb et al. (2010) found the lack of inspection of safety equipment in high school laboratories. There should be a regular inspection of laboratory fume hood, and most recent results of fume hood inspection post necessarily on the face of fume hood for latest information such as the date of the inspection, name of the inspector and the test results in feet per minute (fpm). (Foster, 2004). Annual inspection programs in a university with proper safety management can improve the maintenance issue of the fume hood. 


\section{Macrothink}

\subsection{Factor 3. Proper Chemical Storage}

The third factor, proper chemical storage, had three safety items and accounted for $10.48 \%$ of the total variance. Proper chemical storage in the chemical laboratories can minimize the incompatibilities and occupational exposure to chemicals as figure 3 shows severe chemical management in a research laboratory of the surveyed university. Balkhiour (2011) found a lack of chemical storage strategy coupled with bad ventilation scenario in the selected university laboratories. Mogopodi et al. (2015) found incompatible chemical storage in a junior secondary school laboratories.

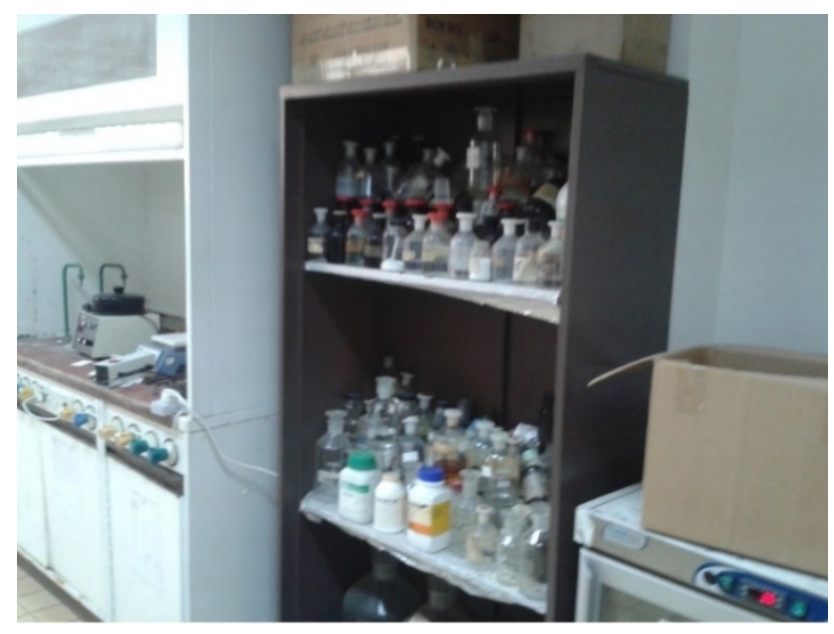

Figure 3. Bad chemical management in a chemical laboratory

Improper storage of corrosive materials (above eye level) can cause severe tissue damage, particularly to the eye. The use of flammable storage cabinets can reduce the laboratory fire accidents as mentioned by (Foster, 2004) that approved flammable liquid storage cabinets must use for flammable liquids storage. Regular household refrigerators must not use for flammable liquid storage.

Third item (FHCH02) in the third factor; Fume hood is not used as permanent storage for chemicals attained high loading and can associate with proper chemical storage. At once as excessive storage of chemicals in the fume hood will decrease its efficiency as an outcome of improper chemical storage. Fume hood can be the most likely site in the lab where a chemical incident can occur, and its choice for chemical storage can trigger more serious lab incident. So, chemicals should never be stored in the fume hood to make sure its optimum performance and containment except for the chemicals that need for the work-in-progress. As figure 4 shows improper use of fume hood with extended chemical storage by laboratory staff. 


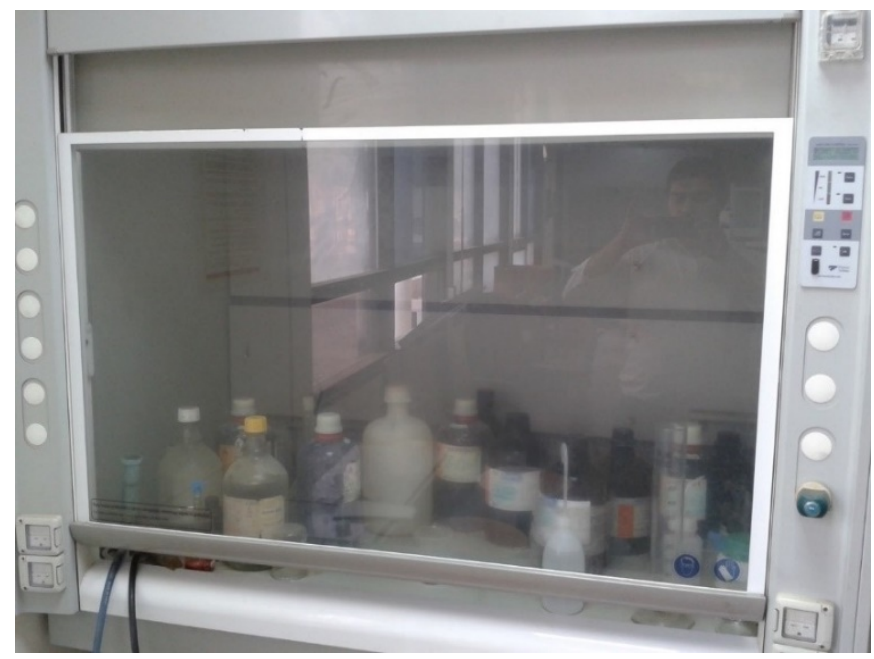

Figure 4. Improper use of fume hood (chemical handling accessories) by laboratory staff

Chemical storage is a part of laboratory chemical management which demands the involvement of all academic key players. From purchasing of chemicals, handling, labeling, and storage up to disposal need a professional approach to minimize their potential risks. A good inventory assists in proper maintenance of chemical safety of a laboratory. It also allows efficient use of resources as it helps in tracking of resources that is, what is the chemical use for, how it use and what goes to waste. Because an inventory identifies quantities and physical locations of chemicals, it can be used as a reference to guide purchases and ensure that only needed supplies purchased. It reduces stockpiling of additional materials and minimizes the costs and management of waste. Further, with an inventory, it becomes possible to organize chemicals by properties. Foster (2004) Highlighted in his article that Improper chemical storage can enhance the severity of laboratory incident like incompatible chemicals can mix and create a fire hazard, toxic fumes, and explosions in case of a chemical spill or fire in the laboratory premises. So, it is mandatory to store chemical according to their hazard category and compatibility by following own MSDS. It is important to educate the laboratory workers about the proper chemical storage practices (Foster, 2004).

\subsection{Factor 4. Proper Use of Fume Hood for Chemical Handling}

The fourth factor, proper use of fume hood, account for $9.07 \%$ of the total variance with four essential safety items. Proper use of fume hood such as; fume hood and secondary containment can prevent laboratory staff from chemical exposure. As earlier we have already discussed the fume hood maintenance, proper use of fume hood can also relate with its fume hood performance. Use of fume hood is important in the case of dealing with toxic chemical vapors, dust, gasses, and volatile substances (Foster, 2004). Fume hood sashes should lower down or adjust the position marked on the Standard Operating Configuration (SOP) sticker posted on the fume hood, when not in active use. Both chemicals and equipment should be placed at least six inches from the fume hood face to allow proper airflow. The use secondary containment (such as trays) near sink or drain can avoid the chances of costly cleanup and 
potentially hazardous conditions in the event of a spill (Foster, 2004). Safety item related to Secondary containment used near sinks and drains (FHCH09) skipped from factor 4 as it was not suitable for logical labelling of factor 4 .

\subsection{Factor 5. Laboratory Safety Labelling}

The fifth factor, laboratory safety labeling, had two items and accounted for $8.05 \%$ of the total variance. The use of refrigeration in the laboratories is evident for specific chemical storage, and labeling of refrigerator or freezers designated for chemical storage can be useful to avoid food storage in it. Regular inspection and testing should be conducted to ensure the standard practices such as store food or beverages outside the laboratory active working area and labeled the designated refrigerator "Food Only-No Chemicals." (Foster, 2004).

Foster (2004) mentioned that labeling of chemical containers is significant to prevent from chemical incompatibilities. Karapantsios et al., 2008) \& Artdej (2012) found that traditional method of teaching of safe-handling and hazard labelling was not enough to equip safety knowledge of students. At least, chemical containers must labelled with a chemical name, but manufacture's label can be best comparatively with more health and physical hazards information. In the case of small containers, code or numbering according to user's lab notebook can be used for labelling. A recent study about the assessment of chemical management practices showed the lack of labelling of chemical containers and faded labelling in the schools laboratories of Botswana (Gaborone), clearly an indication incompatibilities that can cause chemical accidents in the laboratories (Mogopodi et al., 2015). Kristopher et al. (2013) also investigated deficiencies regarding laboratory labelling \& posting.

\section{Conclusions}

This study concludes that chemical safety in the academic laboratories can be influenced by five extracted factors through EFA. The results of this study would undoubtedly prove useful in the development of chemical safety management in academic laboratories. Training on handling and storage of chemical is essential as it empowers laboratory staff to be able to prevent potential accidents and to have knowledge of how to respond in the event of a chemical accident. This study recommend the promotion of sound chemical management, which can promote through induction of teachers, students and support staff through workshops and a chemical safety awareness campaign. Areas such as availability of laboratory safety documents and maintenance of fume hood demand the involvement of top management with effective university's inspection programs.

\section{Acknowledgements}

We acknowledge the cooperation of University's Deanship of Graduate Studies and laboratory staff of the surveyed academic departments and Excellence research centers to conduct this study. 


\section{References}

Abbas, M., Zakaria, A. M., \& Balkhyour, M. A. (2015). Investigation of safety facilities and safe practices in chemical laboratories of a Saudi university. Journal of Environment and Safety. http://doi.org/10.11162/daikankyo.E15RP1001

Artdej, R. (2012). Investigating undergraduate students' scientific understanding of laboratory safety. Procedia-Social and Behavioral Sciences, 46, 5058-5062. http://dx.doi.org/10.1016/j.sbspro.2012.06.385

Balkhiour, M. A. (2011). Evaluation of the Safety Status in Some University Laboratories. Journal of King Abdulaziz University: Meteorology, Environment \& Arid Land Agriculture Sciences, 22(1). http://dx.doi.org/10.4197/met.22-1.14

Foster, B. L. (2004). Laboratory safety program assessment in academia. Chemical Health and Safety, 11(5), 6-13. http://dx.doi.org/10.1016/j.chs.2004.05.016

Hill, R. H. (2007). The emergence of laboratory safety. Journal of Chemical Health and Safety, 14(3), 14-19. http://dx.doi.org/10.1016/j.jchas.2006.10.001

Karapantsios, T. D., Boutskou, E. I., Touliopoulou, E., \& Mavros, P. (2008). Evaluation of chemical laboratory safety based on student comprehension of chemicals labelling. Education for chemical engineers, 3(1), e66-e73. http://dx.doi.org/10.1016/j.ece.2008.02.001

Langerman, N. (2009). Laboratory safety?. Journal of Chemical Health and Safety, 16(3), 49-50.

Lestari, F., Kurniawidjaja, M. L., \& Hartono, B. (2015). Baseline survey on the implementation of laboratory chemical safety, health and security within health faculties laboratories at Universitas Indonesia. Journal of Chemical Health and Safety. http://dx.doi.org/10.1016/j.jchas.2015.11.002

Marendaz, J. L., Suard, J. C., \& Meyer, T. (2013). A systematic tool for Assessment and Classification of Hazards in Laboratories (ACHiL). Safety science, 53, 168-176. http://dx.doi.org/10.1016/j.ssci.2012.10.001

Meyer, T. (2012). How about safety and risk management in research and education?. Procedia Engineering, 42, 854-864. http://dx.doi.org/10.1016/j.proeng.2012.07.478

Mogopodi, D., Paphane, B., \& Petros, S. (2015). Assessment of chemical management practices and safety in junior secondary school laboratories in Gaborone. Journal of Chemical Health and Safety, 22(5), 17-27. http://dx.doi.org/10.1016/j.jchas.2015.01.001

National Research Council (US). Committee on Prudent Practices for Handling, \& Disposal of Chemicals in Laboratories. (2011). Prudent practices in the laboratory: handling and disposal of chemicals. National Academies Press.

Nunnally, J. C. (1987). Teoría psicométrica, Editorial Trillas. México,. 


\section{Macrothink}

Journal of Safety Studies

ISSN 2377-3219

2016, Vol. 2, No. 1

Occupational Safety and Health Administration. Occupational Exposure to Hazardous Chemicals in Laboratories; 29CFR; Part 1910.1450, 1990.

Peplow, M., \& Marris, E. (2006). How dangerous is chemistry?. Nature, 441(7093), 560-561.

Richards-Babb, M., Bishoff, J., Carver, J. S., Fisher, K., \& Robertson-Honecker, J. (2010). Keeping it safe: Chemical safety in the high school laboratory. Journal of Chemical Health and Safety, 17(1), 6-14. http://dx.doi.org/10.1016/j.jchas.2009.05.001

Van Ryan Kristopher, R. G., Lamela, N. C., \& Alcantara, R. (2013). Preliminary evaluation of laboratory practices in Cebu Doctors' University, Philippines. Journal of Chemical Health and Safety, 20(4), 25-30. http://dx.doi.org/10.1016/j.jchas.2013.03.490

Wu, T. C., Liu, C. W., \& Lu, M. C. (2007). Safety climate in university and college laboratories: Impact of organizational and individual factors. Journal of Safety Research, 38(1), 91-102. http://dx.doi.org/10.1016/j.jsr.2007.01.003

\section{Copyright Disclaimer}

Copyright for this article is retained by the author(s), with first publication rights granted to the journal.

This is an open-access article distributed under the terms and conditions of the Creative Commons Attribution license (http://creativecommons.org/licenses/by/3.0/). 